\title{
The Impact of Task Type and Cognitive Style on Vocabulary Learning
}

\author{
Gholam Reza Haji Pour Nezhad ${ }^{1} \&$ Nasrin Shokrpour ${ }^{2}$ \\ ${ }^{1}$ Department of English, University of Social Welfare and Rehabilitation Sciences, Tehran, Iran \\ ${ }^{2}$ Department of English, School of Paramedical Sciences, Shiraz University of Medical Sciences, Shiraz, Iran \\ Correspondence: Nasrin Shokrpour, Shiraz University of Medical Sciences, Shiraz, Iran. Tel: 98-711-228-9113. \\ E-mail: shokrpourn@gmail.com
}

Received: June 11, 2012 Accepted: June 26, 2012 Online Published: July 25, 2012

doi:10.5539/elt.v5n9p17 URL: http://dx.doi.org/10.5539/elt.v5n9p17

\begin{abstract}
Vocabulary knowledge influences the learners' performance so remarkably that success in all language skills is closely related to it. This vital role necessitates studies focusing on the most effective programs of teaching vocabulary. In this study, we aimed to explore the impact of static versus dynamic task type and the possible interaction with field dependence/independence cognitive style on learning English vocabulary among intermediate EFL learners. Eighty four female EFL learners studying at the BS level at the University of Social Welfare and Rehabilitation Sciences aged 19-25 were randomly selected and given a Cognitive Style Test and a Nelson Proficiency Test (2000 A) to be assigned to either of the control and experimental groups matched for their vocabulary knowledge and cognitive style. Although the two groups were exposed to identical reading passages during classes held twice a week in the four-month treatment period, the control group received vocabulary instruction through static task type technique based on the traditional approach to teaching vocabulary while the experimental group underwent dynamic task type technique. The Nelson Proficiency Test was once more used as the post-test to show the differences in vocabulary gain in the two groups. The collected data were analyzed through ANOVA, using SPSS software. The results showed that vocabulary instruction led to favorable results among field-dependent learners taught by the dynamic task type technique and poorest performance in field-dependent students exposed to the static task type technique while field-independent learners better performed through the static task-type technique. Task type significantly influences vocabulary learning and may marginally affect reading comprehension performance.
\end{abstract}

Keywords: task-type, static task, dynamic task, task-based instruction, field dependence/independence

\section{Introduction}

After decades of neglect, in the past two or three decades L2 vocabulary learning and teaching has become an object of considerable interest among researchers, teachers, and materials developers (Carter, 1988; Coady \& Huckin, 1997; Nation, 1990; Schmitt \& McCarthy, 1997). According to Schmitt (1997), a vocabulary learning strategy is any strategy that results in the learning of vocabulary. This particularly covers vocabulary teaching strategies as well because they are also meant to lead to vocabulary learning. Nowadays, it is generally accepted that vocabulary teaching should be part of the syllabus, and taught in a well-planned and regular basis. Some authors, following Lewis (1993), argue that vocabulary should be at the centre of language teaching, because 'language consists of grammaticalized lexis, not lexicalised grammar'. Read's review of the field (2004) has revealed a lack of research on issues concerning classroom-teaching of vocabulary. Meanwhile, there is nothing more than "good advice" on how to teach words offered by Nation $(1990,2001)$ and Lewis $(1993)$. Therefore, vocabulary teaching, using an effective technique, needs to be established as an area of research.

Regarding research strategies in dealing with teaching vocabulary, this area must fit into a greater and broader framework of a language course. Seeing a language course as consisting of any of the following four strands is one way of ensuring that there is a balanced range of learning opportunities:

A. Learning from meaning-focused input- learning through listening and reading

B. Deliberate language-focused learning- learning from being taught sounds, vocabulary, grammar, and discourse (sometimes called form-focused instruction, language-focused learning)

C. Learning from meaning-focused out-put- learning by having to produce language in speaking and writing 
(main attention in this strand is on communicating messages)

D. Developing fluency- becoming quick and confident at listening, speaking, reading, and writing (Vocabulary must not only be known, but also readily available for use. This strand aims at helping learners make the best use of what they already know. Fluency relates to each of the four skills of listening, speaking, reading and writing).

Distinguishing these strands means that there is a balance of deliberate learning and incidental learning, of learning from input and output, of learning through oral and written skills, and of learning and fluency development. Regarding the above strands, many researchers in this field believe that learners do not first acquire language as a structural system and then learn how to use this system in communication, but rather actually discover the system itself in the process of learning how to communicate and that teaching vocabulary for active use will be effective if the students are actively involved in the communicative cognitive process of vocabulary teaching/learning at all stages of it (Yagcioglu, 2009 \& Maghsoudi, 2007). De La Fuente (2006) maintains that task-based lessons with a built-in, planned focus on form seem to be more effective than traditional lessons, due to the fewer opportunities for targeted output production and retrieval that traditional techniques offer and also owing to their inability to effectively focus students' attention on targeted forms. According to De La Fuente, task-based lessons designed this way can provide more opportunities for negotiation of meaning and output production.

A simple mapping of the two mentioned task types and the above strands clearly shows that the static task type enjoys the advantages of strands $\mathrm{B}$ and $\mathrm{C}$ while the dynamic task type benefits from strands $\mathrm{A}, \mathrm{C}$, and $\mathrm{D}$. Communicative language teaching approach became popular among second language acquisition (SLA) researchers (Skehan, 2003) in the 1970s. During 1980s, "task" replaced the term "communicative activity" and the task-based language teaching (TBLT) became a new teaching method that has been broadly adopted in language classroom across the globe. Depending on the perspective that language researchers took into classroom practice, tasks were classified in different ways aiming at analyzing and finding a way to understand the learning process and the interaction related to different task types.

One classic dichotomy of task types is static versus dynamic technique (Ellis, 2003). The static type pays more attention to form and transfers information in a linear sequence through the prescribed language and the material is learned consciously while the dynamic task type describes a situation or an action and narrates something. In the latter approach, the speakers are involved in two-way conversations without any prescribed language content, and the material is learned unconsciously. The static task type gives more control to the learner, while the dynamic type emphasizes free uncontrolled production. As the definitions show, the static type provides more linguistic context whereas the dynamic type offers more extra-linguistic context to the learner. Studies have suggested that static tasks are in general easier than dynamic ones (Ellis, 2003).

Field in/dependence is a type of cognitive style introduced by Witkin, et al. (1977) to resemble "the degree to which one perceives analytically or globally" (Hadley, 2003). The ability of a person to extract the 'message' or 'signal' from the 'noise' or irrelevant information or the cognitive restructuring ability is associated with field independent characteristics. Field independence is concerned with the ability to break a complex stimulus into separate elements and to give it a different structure or organization based on previous experiences or restructure it in their own way. If it is difficult to do such a thing, the person is referred to as field dependent (Mancy \& Reid, 2004).

On a language learning level, the learners have to understand language items in their context and to extract them and use them in new contexts (Stern, 1983). For instance, the learner may encounter situations in which s/he has to understand the meaning of an ambiguous sentence or to understand the meaning of a word in its context and use it in other contexts. S/he may be exposed to ill-structured sentences in the process of language learning. In such circumstances, the field in/dependent cognitive style will bear influences on language learning. In other words, field dependency is defined as "the tendency to depend on the field so that the parts embedded within the field are not easily perceived, though that total field is perceived more easily as a unified whole" while field independency is "the ability to perceive a particular relevant item or factor in a field of distracting items" (Brown, 2000).

Field independent learners are analytic, independent, and socially insensitive, while field dependent ones tend to be holistic, dependent, and socially aware (Wyss, 2002). Since field independent learners have greater restructuring skills (Musser, 1998), they are able to extract an embedded simple figure in a field or a complex figure. Research suggests that field in/dependency is under the influence of a lot of factors such as age, sex, hemisphere lateralization, child rearing, and socioeconomic status (Musser, 1998). Although some studies have tried to show that field independence is correlated with more language success especially second language 
learning (Chapelle 1995; Chapelle and Green, 1992; Alptekin and Atakan, 1990), researchers insist that both field dependent and field independent styles may enhance second language learning in their own ways (Tianjero \& Paramo, 1998) so that field independent learners excel at classroom learning which requires analysis and attention to details, and field dependent ones excel at learning the communicative aspects of language learning (Brown, $2000 \&$ Town, 2003).

As mentioned above, numerous studies have been done on vocabulary learning, field in/dependence, and task-type, each in isolation, but, to the best of our knowledge, no research has been done to explore the possible interactions among these three areas when it comes to actual classroom instruction. Our study aims to see how learning vocabulary is affected by task-type mediated by cognitive style while previous studies have focused on the relationship between either cognitive style and vocabulary learning or task-type and vocabulary learning. Nevertheless, we assume that there must be a close link between students' performance on different task types and their cognitive styles. Therefore, the results of this study will shed light on the learning of vocabulary from an information processing perspective, perhaps creating a shift from a uni-dimensional look at learning vocabulary to a multi-fasceted understanding.

\section{Materials and Method}

\subsection{Participants}

In this randomized controlled study, 84 intermediate learners of English aged 19-25 at the University of Social Welfare and Rehabilitation Sciences participated in a four-month treatment. The participants were randomly selected from among a total number of 230 B.Sc. students enrolled for General English courses. Informed consent forms adopted from the sample consent forms given in How to Design and Evaluate Research in Education by Fraenkel and Wallen (2003: 86) were signed by the students to participate in the study.

\subsection{Instruments}

The subjects of the study were then given a Nelson Proficiency Test (2000A) and also the standard Group Embedded Figures Test to assess field dependency. They were matched to form two homogeneous groups based on their vocabulary performance and cognitive style type. Thirty-two reading passages were selected from Academic Encounters as the teaching material of the course for both groups. The same instructor (i.e. the researcher) taught both the experimental and control groups twice a week for a period of four months.

\subsection{Procedure}

The control group experienced the static task-type technique which is the traditional approach to vocabulary instruction, whereby special attention was given to form and the material was to be learned consciously. However, the instructor in the experimental group normally described a situation or an action and narrated something or a situation, and the material was to be learned unconsciously. Following the treatment, the Nelson Test was administered to both groups to find vocabulary gains in the groups and subgroups of the study. ANOVA was used to find if there are any significant differences between and within groups. Furthermore, a test of Homogeneity of Variances was used to ensure about the homogeneity of the two experimental and control groups in terms of their vocabulary performance on the pre-test.

\section{Results}

The results of the test of Homogeneity of Variances are shown in Table 1.

Table 1. Test of Homogeneity of Variances (pre-test)

\begin{tabular}{rlll}
\hline Levene Statistic & df 1 & df 2 & Sig. \\
\hline .938 & 3 & 80 & .473 \\
\hline
\end{tabular}

As shown in Table 1, the significance level confirms the homogeneity of variances in the following subgroups of the study; there was no significant difference between the two groups. The characteristics of each group are shown in Table 2.

Table 2. The characteristics of the subjects participating in each group

\begin{tabular}{llll}
\hline \multicolumn{2}{c}{ Experimental group: (42 subjects) } & \multicolumn{2}{c}{ 2) control group: (42 subjects) } \\
\hline 18 & 24 & 23 & 19 \\
Field-dependent & Field-independent & Field-dependent & Field-independent \\
\hline
\end{tabular}


One-way ANOVA was run to find the possible differences among the four subgroups of the study. Table 3 summarizes the results.

Table 3. The comparison of both groups in the post-test

\begin{tabular}{llccc}
\hline & Sum of Squares & df Mean Square & F & Sig. \\
\hline Between Groups & 912.023 & 3298.76 & 19.319 & .000 \\
Within Groups & 1398.430 & 8015.361 & & \\
Total & 2402.481 & 83 & & \\
\hline
\end{tabular}

The results of ANOVA for the post-test, as shown in Table 3, reject the equality of means in the post-test. To locate the exact differences, the Tukey Test was used. The results are shown in Table 4.

Table 4. The result of post-test in field independent subjects

\begin{tabular}{|c|c|c|c|c|c|c|c|}
\hline Group & mean & $\begin{array}{r}\text { Std. } \\
\text { Deviation }\end{array}$ & Variance & Skewedness & Kurtosis & $\min$ & $\max$ \\
\hline dynamic & 27.6899 & 2.89289 & 8.369 & -.775 & .021 & 21.00 & 39.00 \\
\hline static & 28.2647 & 5.66287 & 32.088 & -.391 & -1.260 & 16.00 & 37.00 \\
\hline
\end{tabular}

According to the data in Tables 4 and 5, it can be observed that the experimental (dynamic) group with a mean of 28.735 performed better than the control (static) group with a mean of 26.600. Table 6 also shows the significance of this superiority. Furthermore, field-independent learners with a mean of 27.977 performed only marginally better than field-dependent subjects with a mean of 27.357 .

Table 5. The result of post-test in field dependent subjects

\begin{tabular}{llllllll}
\hline Group & mean & $\begin{array}{l}\text { Std. } \\
\text { Deviation }\end{array}$ & Variance & Skewedness & Kurtosis & $\min$ & $\max$ \\
\hline dynamic & 29.7801 & 2.619643 & 6.898 & -.569 & -.843 & 23.00 & 37.00 \\
\hline static & 24.9354 & 4.148985 & 17.302 & .947 & .765 & 20.00 & 31.00 \\
\hline
\end{tabular}

As observed in Tables 4 and 5, the largest and smallest means belong to the FD Dynamic group with a mean of 29.7801 and FD Static group with a mean of 24.9354, respectively while the differences within the FI group (static versus dynamic) are small and not significant. On the other hand, FI students with a mean of 27.9773 have performed marginally better than FD students with a mean of 27.35775.

Table 6 displays detailed differences among the subgroups of the study.

Table 6. Turkey HSD comparison of means in the post-test

\begin{tabular}{llllll}
\hline (I) Group & (J) Group & \multicolumn{2}{c}{ 95\% Confidence Interval } \\
\cline { 2 - 5 } & \multicolumn{5}{c}{ Mean Difference (I-J)Std. ErrorSig. Lower BoundUpper Bound } \\
\hline FI - Dynamic & FD - Dynamic & $-3.94100^{*}$ & 1.18018 & $.002-7.4320$ & -1.23789 \\
& FI - Static & -1.66053 & 1.26028 & $.564-4.8925$ & 1.64654 \\
& FD - Static & $3.93462^{\circ}$ & 1.17024 & .007 .8693 & 7.00122 \\
\hline FD - Dynamic & FI - Dynamic4.42130 & 1.18019 & .0031 .3380 & 7.4320 \\
& FI - Static & 1.672147 & 1.19741 & $.128-.4674$ & 5.80654 \\
& FD - Static & $8.26562^{*}$ & 1.10193 & .0005 .3776 & 11.15675 \\
\hline FI - Static & FI - Dynamic & 2.68053 & 1.26027 & $.558-1.6414$ & 4.9665 \\
& FD - Dynamic & -2.674537 & 1.19730 & $.133-5.8064$ & .4677 \\
& FD - Static & $6.591516^{*}$ & 1.18733 & .0002 .4944 & 8.70576 \\
\hline FD - Static & FI - Dynamic & $-3.8752^{*}$ & 1.17104 & $.007-7.0011$ & -.8692 \\
& FD - Dynamic & $-7.36982^{*}$ & 1.10194 & $.000-12.1518$ & -5.37964 \\
& FI - Static & $-4.62314^{*}$ & 1.18731 & $.000-8.6059$ & -2.4954 \\
\hline
\end{tabular}


The significant level of $.564>0.05$ for the differences between FI Dynamic and FI Static groups in the first row shows that intra-group differences among FI students are small and insignificant no matter whether they belong to the Static or the Dynamic groups. In the same row, the significance levels of .002 and $.007<0.05$ show that FD dynamic students performed significantly better than FI dynamic students, who, in turn, performed significantly better than FD Static students.

Meanwhile, the second row of Table 6 shows a significance level of $.003<.05$ for the differences between FD Dynamic and FI Dynamic students where the former performed significantly better. In the same row, a significance level much smaller than .05 shows that FD Dynamic students had a performance better than FD Static ones. The Table, therefore, shows that there are significant differences within the Dynamic group (FI versus FD learners who were taught through the dynamic task-type technique, $p=.002$ ) and within the Static group (FI versus FD learners who were taught through the static task-type technique, $p=.000$ ) as well as within the FD group (FD learners taught through the static versus dynamic task-type techniques, $p=.000$ ). However, as shown in the Table, there were no significant differences in the performance of the FI group (FI learners taught through the static versus dynamic task-type techniques, $\mathrm{p}=.558$ ).

\section{Discussion}

There was an attempt in this study to determine the possible effects that task type and the cognitive style field dependence/independence have on learners' vocabulary gains in a course of study. The results can be classified into two main groups. Firstly, attention should be focused on intergroup differences. On the one hand, we had the experimental group (Dynamic task type) versus the control group (Static task type). As mentioned in the results section, the experimental group performed significantly better than the control group. According to Ellis (2003) and based on the procedures of the study, the dynamic task type comprises description, narration, extra-linguistic contextualization, two-way conversation, and more uncontrolled speech production. By contrast, the static task type focuses more on form, linear sequencing, prescribed language, and conscious learning. The results of the study showed that instruction through the former was more successful than that through the latter. On the other hand, we had the field-dependent group versus the field-independent group. These two groups performed statistically similar although field-independent students performed marginally better.

On the second level of comparison, the intra-group differences were taken into account. In the experimental/dynamic group, field-dependent and field-independent learners performed statistically similar. In other words, the dynamic task type did not cause significant differences in performance between the two cognitive styles. In comparison, the field-dependent and field-independent students in the control/static group produced significantly different results so that the latter outperformed the former. All in all, it was noticed that field-dependent learners were more sensitive to task-type than field-independent learners. In other words, it does not matter much to field-independent learners whether they are taught through the static or the dynamic task-type, whereas it does to the field-dependent learners, who show the best performance among all subgroups when they are taught by the dynamic task-type and the worst of all when they are taught through the static task-type. Meanwhile, regarding field-independent learners, although their performance does not significantly differ, whether in the static or the dynamic group, they show a trend of better performance with static task-type. Based on previous studies (Nation and Carter, 1989; Brown, $2000 \&$ Town, 2003), the potential sources of difference between the performance of field dependent and field independent students may be attributable to the difference between the two groups in the kind of reasoning, the restructuring ability and the use of strategies in processing information. Yet, it is important to know that these cognitive differences are mediated by task-type so that a specific task-type may create a bias against one of the two groups.

\section{Conclusion}

It seems that materials developers, course designers, and test constructors should pay special attention to a balanced recipe in which neither of the two cognitive styles is placed at a disadvantage. It is recommended that they make a balance between deliberate learning and incidental learning, between learning from meaning-focused input/output and form-focused instruction, between cognitive restructuring demands and global understanding (Mancy and Reid, 2004), between controlled and free production, and between socially insensitive and socially aware situations (Wyss, 2002). In line with Town (2003), it is also recommended that despite the traditional myth that field-independence is correlated with more language learning success (Chapelle, 1995; Chapelle and Green, 1992; Alptekin and Atakan, 1990), field dependent and field independent styles each enhances language learning in its own way. Other research studies also support this suggestion (Salamian, 2002 \& Salmani, 2006). 


\section{Acknowlegement}

We would like to thank all the participants of this study for their tolerance and cooperation.

\section{References}

Alptekin, C., \& Atakan, S. (1990). Field dependence-independence and hemisphericity as variables in L2 achievement. Second Language Research, 6, 135-149. http://dx.doi.org/10.1177/026765839000600203

Brown, H. D. (2000). Principles of Language Learning and Teaching (4th ed.). Addison Wesley Longman, Inc.

Carter, G. (1988). The relationship of field-dependent/independent cognitive style to Spanish language proficiency. Modern Language Journal, 72(5), 21-30. http://dx.doi.org/10.1111/j.1540-4781.1988.tb04163.x

Chapelle, C. (1995). Field dependence/independence in L2 classroom. In J, Raid (ed.), Learning Styles in the ESL/EFL Classroom. Boston: Heinle and Heinle.

Chapelle, C., \& Green, P. (1992). Field independence/dependence in second-language acquisition research. Language Learning, 42, 47-83.

Coady, \& Huckin. (Eds). (1997). Second Language Acquisition: A Rational for Pedagogy. Cambridge: Cambridge Uni. Press.

De la Fuente, M. (2006). Classroom L2 vocabulary acquisition: Investigating the role of pedagogical tasks and form-focused instruction. Language Teaching Research, 10(3), 263-295. http://dx.doi.org/10.1191/13621688061r196oa

Ellis, R. (2003). Task-based Language Learning and Teaching. New York: Oxford University Press.

Hadley, A. (2003). Teaching Language in Context (Third Edition). Boston: Heinle \& Heinle Publishers.

Lewis, M. (1993). The Lexical Approach: The State of ELT and the Way Forward. Hove, England: Language teaching publications.

Mancy, R., \& Reid, N. (2004). Aspects of Cognitive Style and Programming. 16th Workshop of the Psychology of Programming Interest Group. Retrieved from www.ppig.org

Maghsoudi, M. (2007). Type of Task and Type of Dictionary in Incidental Vocabulary Acquisition. South Asian Language Review, 17(2), 16-28.

Musser, T. (1998). Individual Differences: How Field Dependence-independence Affects Learners. Retrieved from http://www.personal.psu.edu/staff/t/x/txm4/paper1.html

Nation, I. S. P. (1990). Teaching and Learning Vocabulary. New York: Newbury House.

Nation, I. S. P. (2001). Learning Vocabulary in Another Language. Cambridge: Cambridge University Press.

Nation, P., \& Carter, R. (ed.). (1989). Vocabulary Acquisition: special issue of AILA [Association Internationale de Linguistique Appliquée] Review, 6. On Board Communications for Passenger Care, 1985, MSC/Circ 673, IMO, London.

Yagcioglu, O. (2009). Jazzing up our classes with different Vocabulary teaching activities. Retrieved from www.eaborg.tr/eab/oc/egtconf/pdfkitab/pdf/10.pdf

Read, J. (2004). Research in teaching vocabulary. Annual Review of Applied Linguistics, 24, $146-161$. http://dx.doi.org/10.1017/S0267190504000078

Salamian, V. (2002). The Relationship between Field-dependence/independence and Performance on LC Global and Local Questions. Unpublished MA thesis, Shiraz University, Iran.

Salmani, M. A. (2006). Cognitive styles as a factor affecting task-based reading comprehension test scores. TESL Canada Journal, 24, 1.

Schmitt, N. (1997). Vocabulary learning strategies. In N. Schmitt, \& M. McCarthy, (Eds.), Vocabulary: Description, Acquisition and Pedagogy (pp. 199-227). Cambridge: Cambridge University Press.

Schmitt, N., \& McCarthy M. (Eds.). (1997). Vocabulary: Description, Acquisition and Pedagogy. Cambridge: Cambridge University Press.

Skehan, P. (2003). Focus on form, tasks, and technology. Computer Assisted Language Learning, 16, $391-411$. http://dx.doi.org/10.1076/call.16.5.391.29489

Stern, H. H. (1983). Fundamental Concepts of Language Teaching. Oxford: Oxford University Press. 
Tianjero, C., \& Paramo, M. F. (1998). Field dependence-independence in second-language acquisition: Some forgotten aspects. The Spanish Journal of Psychology, 1(1), 32-38.

Town, D. A. (2003). Cognitive Style and Learning Strategies. Retrieved from http://www.monografias.com/trabajos16/learning-styles/learning-styles.shtml

Witkin, H. A., Moore, C. A., Goodenough, D. R., \& Cox, P. W. (1977). Cognitive styles and their educational implications. Review of Educational Research, 47, 1-64.

Wyss, R. (2002). Field independent/dependent learning styles and L2 acquisition. The Weekly Column, Article 102. Retrieved from www.eltnewsletters.com/back/June2002/ art1022002.htm 